\title{
Eucalyptus oil nanoemulsion-impregnated chitosan film: antibacterial effects against a clinical pathogen, Staphylococcus aureus, in vitro
}

This article was published in the following Dove Press journal:

International Journal of Nanomedicine

I October 2015

Number of times this article has been viewed

\author{
Saranya Sugumar \\ Amitava Mukherjee \\ Natarajan Chandrasekaran \\ Centre for Nanobiotechnology, \\ VIT University, Vellore, India
}

\begin{abstract}
Eucalyptus oil (Eucalyptus globulus) nanoemulsion was formulated using lowand high-energy emulsification methods. Development of nanoemulsion was optimized for system parameters such as emulsifier type, emulsifier concentration, and emulsification methods to obtain a lower droplet size with greater stability. The minimized droplet diameter was achieved using the high-energy method of ultrasonication. Tween 80 was more effective in reducing droplet size and emulsion appearance when compared to Tween 20. Stable nanoemulsion was formulated with Tween 80 as a surfactant, and the particle size was found to be $9.4 \mathrm{~nm}(1: 2 \mathrm{v} / \mathrm{v})$. The eucalyptus oil nanoemulsion was impregnated into chitosan $(1 \%)$ as a biopolymer in varying concentrations. Further, the film was characterized by moisture content, microscopic study, X-ray diffraction, and Fourier transform infrared spectroscopy. Also, the film with and without nanoemulsion was evaluated against Staphylococcus aureus. The nanoemulsion-impregnated chitosan film showed higher antibacterial activity than chitosan film. These results support the inclusion of nanoemulsion-impregnated chitosan film in wound management studies.
\end{abstract}

Keywords: essential oil, emulsion, biopolymer, impregnation, thin film, wound isolate

\section{Introduction}

Wounds are physical injuries that occur due to an accident that results in a breaking or opening of the skin. The exposed tissue leads to a moist and natural medium for microbial growth and proliferation. The bacterial strain Staphylococcus aureus, a Gram-positive opportunistic bacterium, is found to be present in skin abrasions and burns and can lead to infection and sepsis. ${ }^{1}$ The process of wound healing is a complex and dynamic healing process that involves three important phases: inflammation, proliferation, and tissue remodeling. ${ }^{2,3}$

The use of essential oils has been reported for human diseases for centuries because they contain enriched bioactive compounds of medicinal value. ${ }^{4}$ In recent years, the majority of the world's population now depend on traditional medicine because of the eco-friendliness and cost-effective production. ${ }^{5}$ The permeation of essential oil compounds is faster in the skin due to their volatile nature and fat-soluble substances present in them. ${ }^{6,7}$ The plant-based essential oils have been shown to possess antimicrobial, wound-healing, insecticidal, and pharmaceutical properties. ${ }^{2}$

For application studies, essential oil-based emulsion formation is important due to the hydrophobic nature of the oil system, and it is necessary to formulate a soluble nature using an emulsification technique. Emulsions are mixtures of two immiscible liquids that are stabilized by a surfactant. Emulsion droplets that are extremely small in
Chandrasekaran

Centre for Nanobiotechnology, CBMR

VIT University, Vellore-6320I4, India

$\mathrm{Tel}+914162202624$

Fax +91 4162243092

Email nchandrasekaran@vit.ac.in submit your manuscript | www.dovepress.com

Dovepress

http://dx.doi.org/10.2147/IJN.S79982
International Journal of Nanomedicine 2015: 10 (Suppl I: Challenges in biomaterials research) 67-75 
size, ranging from 20-200 nm, are called nanoemulsions. To prepare nanoemulsions, the high-energy methods are widely employed; these include microfluidization, high-pressure homogenization, and ultrasonication. The method that is most widely used is ultrasonication, because it is economical and easy to use. ${ }^{8-10}$ The antimicrobial oil-in-water nanoemulsion was shown to possess a broad spectrum of activity against bacterial pathogens due to the reduced droplet diameter. ${ }^{11,12}$ Recently, by our group, the ultrasonic emulsification of eucalyptus oil nanoemulsion was studied, and size reduction was achieved with the aid of ultrasonication time. Also, the stabilized emulsion system was studied for topical application against $S$. aureus by in vitro and was shown to be nonirritant, and high wound healing activity was observed in Wistar rats in an in vivo experiment. ${ }^{13}$

The new generation of wound dressings is the product of the combination of antibacterial agents onto/into the biodegradable polymer material. Efforts are made to ensure a sustained release of active compound into the wounded site so that the infection is highly reduced. An effective means of remedy, at the wounded site is the use of antimicrobial bandages/scaffolds with which the active compound is used in minimal amounts and ensures that the healing activity is efficient at that site. ${ }^{14}$

In recent years, application studies have focused on biodegradable films made from natural polymers in pharmaceutical and food industries. Such polymers may be proteins of plant or animal origin and biological materials. Their chemical nature determines the enhancement of physical and mechanical properties of the resulting film. ${ }^{15-17}$ The use of synthetic chemicals such as polyvinyl alcohol and polyvinylpyrrolidone based films had developed resistance in microbes, and also was not applicable for a longer usage in the environment due to non degradable properties. The use of plastic-based products has become part of our life and led to the rapid emergence of the plastic industry in the past several decades. But the films made of synthetic polymers are non-biodegradable and lead to serious ecological problems, resulting in environmental pollution. ${ }^{18}$

Chitosan is the second most abundant polysaccharide from arthropod exoskeletons. It is a nontoxic, biodegradable, antibacterial, chelating biopolymer produced by the deacetylation of chitin, an abundant organic resource. ${ }^{19-21}$ Natural biopolymeric films with essential oil have potential advantage over the synthetic products since they are totally biodegradable and are derived from biological materials. ${ }^{22}$ Particularly in biomaterials research, they have been found to have enhanced healing rates and tissue-repair strengths. ${ }^{23-25}$ The casting solution of chitosan with bioactive compounds have been widely studied via the incorporation of drugs, proteins, dyes, ${ }^{26-28}$ essential oils, ${ }^{29,30}$ and phenolic compounds. ${ }^{31}$ Chitosan films have been incorporated with thyme oil for potential wound-healing applications. ${ }^{32}$ In most studies, a nonionic surfactant was used in essential oil film-forming solution to achieve solubility of oil and to make homogeneous film solution. ${ }^{33-35}$ Instead, these can be formulated into emulsion based film formation to have more stability and homogeneous solution.

The present study was focused on impregnating eucalyptus oil nanoemulsion into chitosan to develop a film. Further, this was studied for physicochemical properties through moisture content, microscopic studies, X-ray diffraction, and Fourier transform infrared (FTIR) spectroscopy studies. Finally, the obtained nanoemulsionimpregnated chitosan film (NE-CH) was evaluated against $S$. aureus by in vitro studies such as agar disc diffusion and plate count method.

\section{Materials and methods Materials}

Chitosan powder (90\% deacetylated), Tween 80, Tween 20, and acetic acid were obtained from Sigma-Aldrich Co. (St Louis, MO, USA). Eucalyptus oil and nutrient agar were purchased from HiMedia (Mumbai, India). Ultrapure water obtained using a Cascada $^{\text {TM }}$ Biowater System with a resistivity not less than 18.2 $\mathrm{M} \Omega \cdot \mathrm{cm}^{-1}$ was used for the preparation of all solutions. All other chemicals used were of analytical reagent grade.

\section{Methods}

\section{Formulation of eucalyptus oil nanoemulsion}

Oil-in-water nanoemulsion was prepared by the procedure previously reported. ${ }^{36}$ Briefly, oil-in-water nanoemulsion was formulated using eucalyptus oil (6\%), nonionic surfactant (Tween 80; Tween 20), and water (1:2 v/v). Initially, the emulsion was prepared by adding water to oil and surfactant mixture using a magnetic stirrer. Then, the coarse mixture was subjected to ultrasonic emulsification using a $20 \mathrm{kHz}$ sonicator with a maximum power output of $750 \mathrm{~W}$.

\section{Preparation of NE-CH}

Chitosan solution ( $1 \% \mathrm{w} / \mathrm{v})$ was prepared using $1 \%$ acetic acid. After complete mixing, the solution was filtered with Whatman number 1 paper and used for further studies. Different percentages of eucalyptus oil nanoemulsion $(0 \%, 1 \%, 3 \%$, and $5 \% \mathrm{v} / \mathrm{v})$ and chitosan solution were mixed, and this was homogenized using a sonicator for 10 minutes. The film solutions were cast over the evenly leveled acrylic plates and dried at $50-60^{\circ} \mathrm{C}$ and $60 \% \pm 2 \%$ relative humidity for 48 hours. 


\section{Phase contrast microscopy}

The surfaces of the films with and without nanoemulsion were observed with a phase contrast microscope coupled with a camera (Leica DM-2500). The pictures were taken at different magnifications.

\section{Moisture content analysis}

Films with and without nanoemulsion loaded $(3 \times 3 \mathrm{~cm})$ were weighed before and after drying in an oven at $105^{\circ} \mathrm{C}$ for 24 hours. ${ }^{15}$ Moisture content was calculated as follows: moisture content $=M_{0}-M_{f} / M_{f}$ where $M_{0}$ was the initial film weight (mg) and $\mathrm{M}_{\mathrm{f}}$ was the final weight (mg). Moisture content was expressed as milligrams water per milligrams dry solids.

\section{X-ray diffraction studies}

The X-ray diffractograms of the chitosan and nanoemulsion films were characterized with a powdered X-ray diffractometer (model: D8 Advance; Bruker Optik GmbH, Ettlingen, Germany) using Ni-filtered radiation. About $1 \times 1 \mathrm{~cm}$ of the film sample was deposited on the sample holder for scanning the film in the range of $10^{\circ}-60^{\circ}$.

\section{FTIR measurements}

The $\mathrm{CH}$ and NE-CH films were subjected to FTIR by potassium bromide technique in a Nicolet 6700 FT-IR Spectrometer (Thermo Fisher Scientific, Waltham, MA, USA), in the scanning range of 4,000-500 $\mathrm{cm}^{-1}$. FTIR analysis was done to detect the functional groups present in the sample and to study the interactions between the chitosan and nanoemulsionimpregnated films.

\section{Antibacterial activity against clinical pathogen S. aureus \\ Agar disc diffusion method}

The antibacterial activity of $\mathrm{CH}$ and $\mathrm{NE}-\mathrm{CH}$ films $(1 \%, 3 \%$, and $5 \%$ ) was evaluated by agar disc diffusion method against S. aureus Gram-positive bacteria (MTCC 3160; IMTECH, Chandigarh, India). The overnight-grown culture was adjusted to 0.1 optical density (OD) at $600 \mathrm{~nm}$. The plates were previously seeded with $0.1 \mathrm{~mL}$ of adjusted culture $\left(1 \times 10^{7} \mathrm{CFU} /\right.$ $\mathrm{mL})$. The definite size of the film $(5 \mathrm{~mm})$ was kept in the solidified nutrient agar medium in a Petri plate that was incubated for 24 hours at $37^{\circ} \mathrm{C} \pm 1^{\circ} \mathrm{C}$. Each assay was repeated three times and results were plotted as mean \pm standard error.

Plate count assay - spread plate method

Antibacterial activity of chitosan-only and NE-CH films was evaluated according to a protocol, with a slight modification. ${ }^{34}$
The films $(2.5 \mathrm{~cm})$ were transferred to respective test tubes containing $10 \mathrm{~mL}$ of $0.1 \mathrm{OD}$-adjusted $S$. aureus culture. The test tubes were then stored at $28^{\circ} \mathrm{C}-30^{\circ} \mathrm{C}$ for 24 hours in a shaker. A test tube without film and a test tube without organism were taken as controls. Then, $0.1 \mathrm{~mL}$ of each sample was used to prepare serial dilutions that were spread in duplicates on nutrient agar plates. The plates were incubated at $37^{\circ} \mathrm{C}$ for 24 hours. The colonies were counted and calculated by using a dilution factor. The percentage viability of bacterial cells was plotted after 24 hours of incubation at $37^{\circ} \mathrm{C}$. The experiments were done in triplicate and the results were plotted as mean \pm standard error.

\section{Results and discussion Nanoemulsion formation}

The oil-in-water nanoemulsion was formulated using eucalyptus oil and Tween 80 as an organic phase and water as aqueous phase. The volume of $6 \%$ oil was used to formulate the $1: 2$ ratio of the emulsion system. The mean droplet diameter of $9.4 \mathrm{~nm}$ with polydispersity index of 0.124 was determined by particle size analyzer. The polydispersity index less than 0.2 indicates the emulsion droplets are monodispersed. The formulated nanoemulsion was stable even after being subjected to centrifugation for 30 minutes at 3,000 rpm. Also, it was more stable when stored at different temperatures $\left(4^{\circ} \mathrm{C},-20^{\circ} \mathrm{C}\right.$, and $\left.45^{\circ} \mathrm{C}\right)$ compared to the conventional formulation (before sonication). The impact of non-ionic surfactant type on the droplet size of eucalyptus oil nanoemulsion was studied. In the present work, non-ionic surfactants such as Tween 20 and Tween 80 were used to prepare $\mathrm{O} / \mathrm{W}$ (oil in water) nanoemulsion due to their high HLB value (16.7 and 15). Eucalyptus oil concentration $(6 \% \mathrm{v} / \mathrm{v})$, oil-surfactant mixing ratio $(1: 1 \mathrm{v} / \mathrm{v})$, and emulsification time (10 minutes) were kept constant, and nanoemulsions were formulated using different surfactant types (Tween 20 and Tween 80 ). Of the two surfactants, Tween 80 is more effective in reducing the droplet radii as well as the stability than Tween 20 . The low energy emulsification of eucalyptus oil emulsion without sonication was found to be unstable, and phase separated immediately after preparation. Similarly, the results are in agreement with our previous findings, where the nanoemulsion can be formulated with use of non ionic surfactant having droplet radii less than $70 \mathrm{~nm}$ using high intensity ultrasonic waves. . $^{37,38}$

\section{Film microstructure}

The characteristic optical microscopic images of $\mathrm{CH}$ and NE-CH films $(1 \%, 3 \%$, and 5\%) are shown in Figure 1. A smooth and continuous microstructure was observed in chitosan film alone (Figure 1A). More oil droplets 

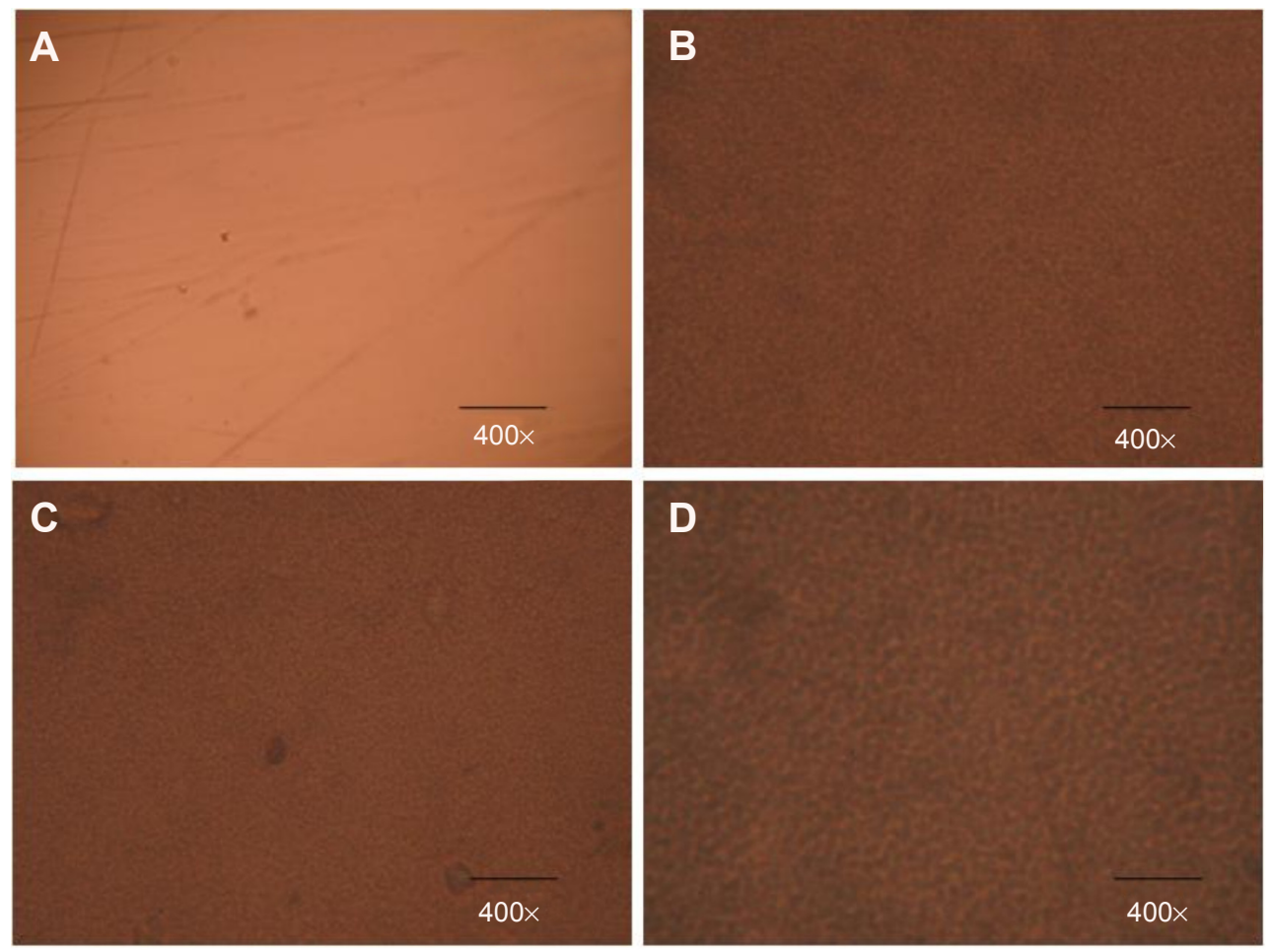

Figure I Microstructure of films by phase contrast microscopy at the magnification of $400 \times$.

Notes: (A) Chitosan-only film. (B) I\% NE-CH. (C) $3 \% \mathrm{NE}-\mathrm{CH}$. (D) $5 \% \mathrm{NE}-\mathrm{CH}$.

Abbreviation: $\mathrm{NE}-\mathrm{CH}$, nanoemulsion-impregnated chitosan film.

were seen with increasing concentration of nanoemulsion and thus were more intimately incorporated into the polymer matrix (Figure 1B-D). A similar morphological structure study was carried out with chitosan film by confocal laser scanning microscopy. ${ }^{39}$

\section{Moisture content}

The hydrophobicity of film provides an indication of resistance to moisture, which is favorable for application studies of pharmaceutical products and in the food and cosmetic industries. ${ }^{14}$ Figure 2 shows the variations of the moisture content in chitosan films for increasing concentrations of nanoemulsion. It can be observed that the moisture content was lowest for films with $5 \%$ of emulsion loaded when compared with films having $0 \%, 1 \%$, and $3 \%$ emulsion. This result is similar to that of Shojaee-Aliabadi et $\mathrm{al}^{40}$ whose films tended to become more hydrophobic due to the oil added to the edible films.

\section{X-ray diffractogram studies}

Chitosan is a polysaccharide that is partially crystalline due to its regular chain and has two reflection falls at $2 \theta=10^{\circ}$ and

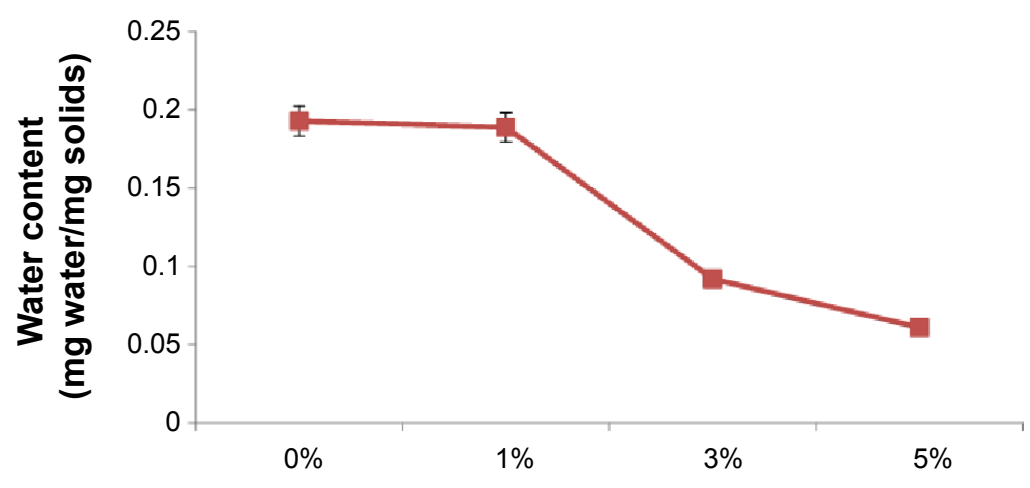

Nanoemulsion content in chitosan film

Figure 2 Moisture content of formulated nanoemulsion-impregnated chitosan films ( $0 \%, 1 \%, 3 \%$, and $5 \%$ ).

Note: Values are given as mean \pm standard error. 


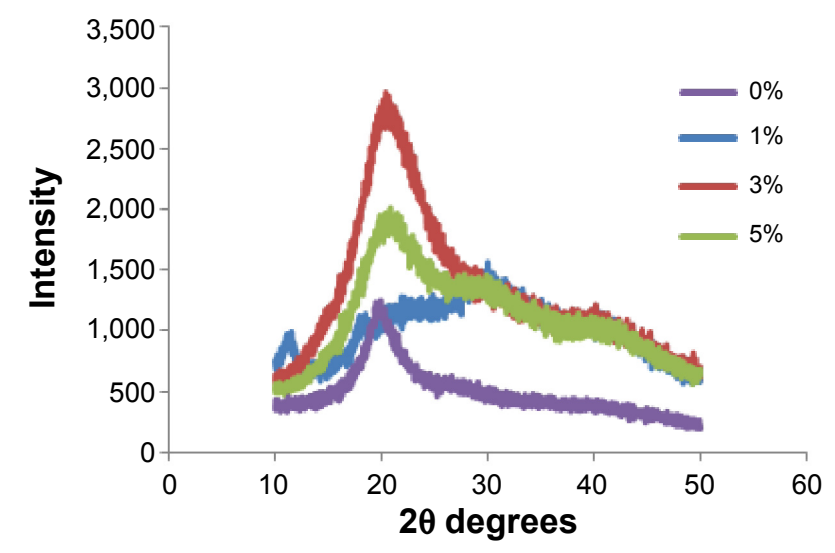

Figure 3 X-ray diffraction patterns of nanoemulsion-impregnated chitosan films $(0 \%, 1 \%, 3 \%$, and $5 \%)$.

$20^{\circ} \cdot{ }^{20}$ The crystallinity of the chitosan films decreased with the increase of nanoemulsion in films, as shown in Figure 3. The reflection around $10^{\circ}$ indicates the presence of the crystal form $I$. The strongest reflection at $2 \theta=20^{\circ}$ corresponds to the crystal form II, as per the recent reports by $\mathrm{Wu}$ et $\mathrm{al}^{41}$ and Pastor et al. ${ }^{42}$ In emulsion-impregnated films, the peak at $20^{\circ}$ became wider, which indicated that the crystallization of chitosan was reduced during the film formation.

\section{FTIR spectroscopy analysis}

FTIR spectroscopy was used to observe the interactions between $\mathrm{CH}$ and NE-CH films. Figure 4 shows the

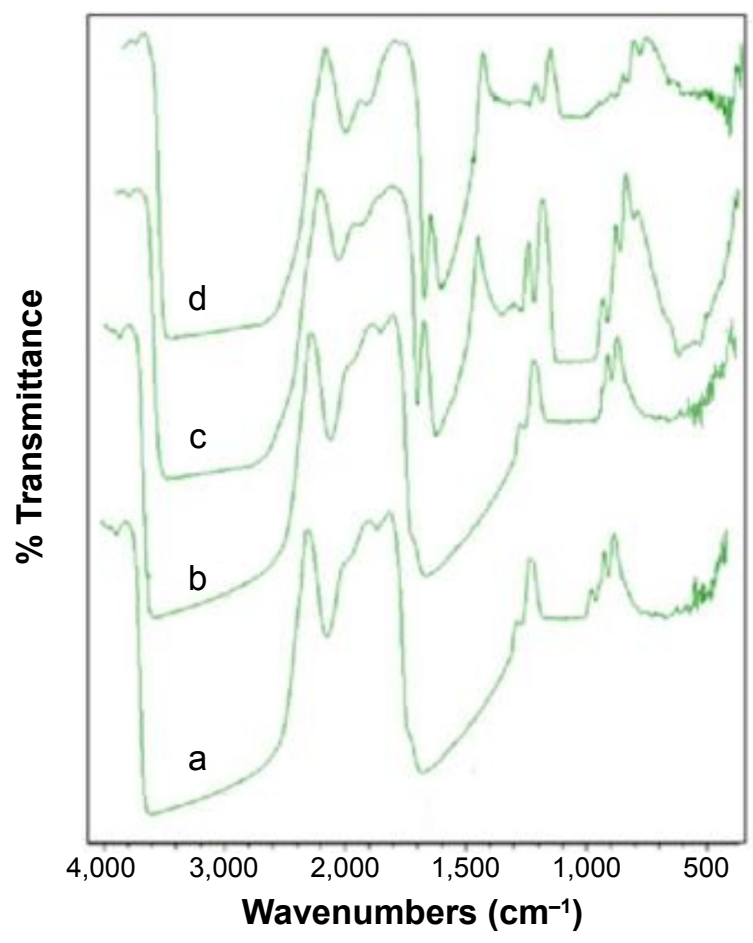

Figure 4 Fourier transform infrared spectra of NE-CHs. Notes: (a) $0 \% \mathrm{NE}-\mathrm{CH}$. (b) $1 \% \mathrm{NE}-\mathrm{CH}$. (c) $3 \% \mathrm{NE}-\mathrm{CH}$. (d) $5 \% \mathrm{NE}-\mathrm{CH}$. Abbreviation: $\mathrm{NE}-\mathrm{CH}$, nanoemulsion-impregnated chitosan film.
FTIR spectra of chitosan and nanoemulsion films (1\%, $3 \%$, and $5 \%$ ). It can be seen that the peak of $\mathrm{N}-\mathrm{H}$ bending in chitosan and $1 \%$ nanoemulsion films located at $1,668.43 \mathrm{~cm}^{-1}$ shifted to $1,735.93 \mathrm{~cm}^{-1}$ with increasing nanoemulsion concentration. ${ }^{16}$ The bands appearing between 2,750 and $3,000 \mathrm{~cm}^{-1}$ in the spectrum of chitosan film are due to stretching vibrations of $\mathrm{C}-\mathrm{H}$ bond in $-\mathrm{CH}_{2}\left(2,930 \mathrm{~cm}^{-1}\right)$ and $-\mathrm{CH}_{3}\left(2,870 \mathrm{~cm}^{-1}\right)$ groups, respectively. ${ }^{43}$ The broad band ranging between 3,500 and 3,100 $\mathrm{cm}^{-1}$ is attributed to $\mathrm{O}-\mathrm{H}$ stretching vibration, and the peak at $1,735 \mathrm{~cm}^{-1}$ suggests the presence of a carbonyl group $(\mathrm{C}=\mathrm{O})$ in the film. The deconvolution of the FTIR area band ranging between 1,600 and $1,800 \mathrm{~cm}^{-1}$ shows that the emulsion incorporation leads to the presence of a new band at $1,740 \mathrm{~cm}^{-1}$, when nanoemulsion is added. These results are similar when essential oil was added to the chitosan films. ${ }^{44}$

\section{Antibacterial activity}

\section{Agar disc diffusion method}

The antibacterial activity of $\mathrm{CH}$ and $\mathrm{NE}-\mathrm{CH}$ films (1\%, 3\%, and $5 \%$ ) were tested against the tested pathogen $S$. aureus by agar disc diffusion method. The inhibitory activity of chitosan films and NE-CH are shown in Figure 5. The increasing order of $1 \%, 3 \%$, and 5\% NE-CH films (Figure 5B-D) showed higher inhibitory activity $(7 \mathrm{~mm}, 11 \mathrm{~mm}$, and $15 \mathrm{~mm}$, respectively) without any bacterial growth around the film, whereas $\mathrm{CH}$ film (Figure 5A) showed $7 \mathrm{~mm}$.

The hydrophilic nature of emulsion-incorporated polymer used in the study was found to have an enhanced inhibitory zone of the tested bacteria (Table 1 ). The $5 \%$ nanoemulsionimpregnated chitosan film showed a higher zone of inhibition than $3 \%, 1 \%$, and $0 \%$ nanoemulsion-impregnated chitosan film. As Hosseini et al mentioned, films containing thyme essential oil in general are very hydrophilic, thus they diffuse faster onto the media with strong inhibition. ${ }^{45}$ The increased antibacterial effect of adding essential oil or bioactive compounds on films against Gram-positive and Gram-negative bacteria has been extensively studied. ${ }^{17,45,46}$ Positive controls rifampicin, vancomycin, and chloramphenicol were tested against the wound isolate, and the results are shown in Table 2. Rifampicin showed the highest inhibition $(29 \mathrm{~mm})$ compared to chloramphenicol $(19 \mathrm{~mm})$ and vancomycin (15 mm).

In order to investigate the antibacterial effect of emulsionimpregnated films further, the in vitro quantitative test was examined. The results show that the control films inhibited the growth of the bacteria at a reduced level, which was due to the high molecular weight of the chitosan (90\%, deacetylation) that was used. This behavior was also observed by Coma et al 


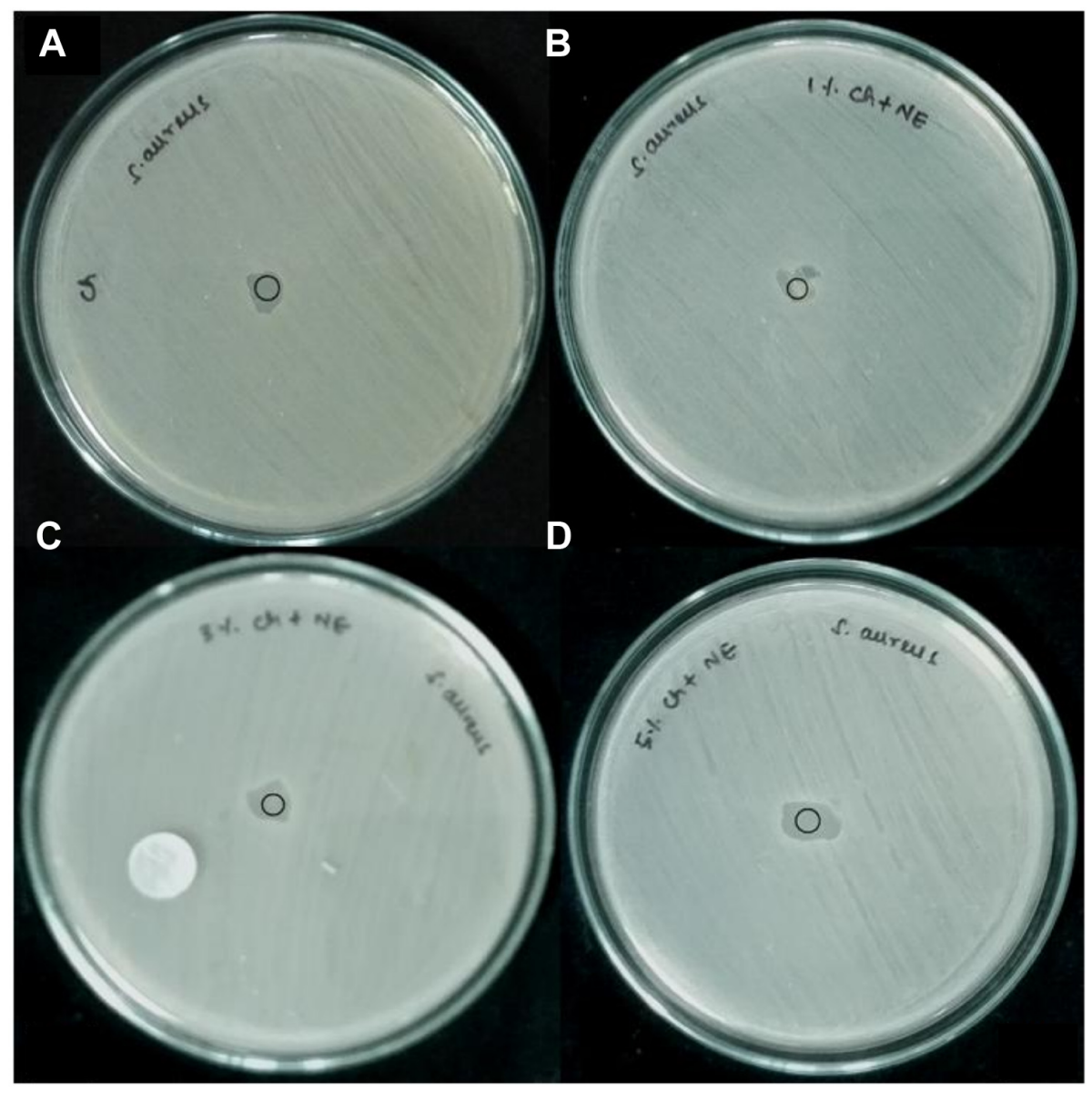

Figure 5 Antibacterial activity of chitosan-only film and NE-CHs against Staphylococcus aureus by agar disc diffusion method on solid medium. Notes: (A) $0 \% \mathrm{NE}-\mathrm{CH}$. (B) $1 \% \mathrm{NE}-\mathrm{CH}$. (C) $3 \% \mathrm{NE}-\mathrm{CH}$. (D) $5 \% \mathrm{NE}-\mathrm{CH}$.

Abbreviation: $\mathrm{NE}-\mathrm{CH}$, nanoemulsion-impregnated chitosan film.

wherein high-molecular-weight chitosan did not diffuse through the adjacent agar media. ${ }^{47}$

\section{Plate count assay}

The antibacterial activity of $\mathrm{CH}$ film and different concentrations of NE-CH films against the wound isolate $S$. aureus was studied by standard plate count method (Figure 6). Different percentages of NE-CH $(1 \%, 3 \%$, and $5 \%)$ with $\mathrm{CH}$ films $(2.5 \times 2.5 \mathrm{~cm})$ and chitosan-only film $(2.5 \times 2.5 \mathrm{~cm})$ were used for the study. As shown in Figure 6E, no viable cells were

Table I Antibacterial activity of nanoemulsion-impregnated chitosan films against the wound isolate Staphylococcus aureus by agar disc diffusion method

\begin{tabular}{lll}
\hline $\begin{array}{l}\text { Antibacterial } \\
\text { agent }\end{array}$ & $\begin{array}{l}\text { Nanoemulsion } \\
\text { content/g chitosan }\end{array}$ & $\begin{array}{l}\text { Inhibitory zone on } \\
\text { solid medium } \mathbf{( m m})\end{array}$ \\
\hline Nanoemulsion- & $0 \%$ & $7 \pm 0.1$ \\
impregnated & $1 \%$ & $7 \pm 0.5$ \\
chitosan films & $3 \%$ & $11 \pm 0.3$ \\
& $5 \%$ & $15 \pm 1$ \\
\hline
\end{tabular}

observed after 24-hour treatments with 5\% emulsion-impregnated films. For 3\% (Figure 6D), 1\% (Figure 6C), and chitosan-only film (Figure 6B), 80\% viable cells were observed after 24 hours. The control plate (Figure 6A) showed 100\% viable cells. It is evident that there is bactericidal activity with the $5 \%$ emulsion-impregnated films. The outcome of the study proves that the NE-CH films with increasing concentration of essential oil showed effective antibacterial activity against $S$. aureus. The reduced antibacterial activity was observed for chitosan-only films (Figure 7A) and $1 \%$ and $3 \%$ NE-CH (Figure 7B and C), due to the biofilm

Table 2 Antibacterial activities of antibiotic discs against the wound isolate Staphylococcus aureus by agar disc diffusion method

\begin{tabular}{ll}
\hline $\begin{array}{l}\text { Positive control } \\
\text { antibiotic disc }(\mathbf{7 ~} \mathbf{~ m m})\end{array}$ & $\begin{array}{l}\text { Zone of inhibition on } \\
\text { solid medium }(\mathbf{m m})\end{array}$ \\
\hline Vancomycin $(30 \mu \mathrm{g})$ & $15 \pm 0.5$ \\
Rifampicin $(5 \mu \mathrm{g})$ & $29 \pm 0.1$ \\
Chloramphenicol $(30 \mu \mathrm{g})$ & $19 \pm 0.2$ \\
\hline
\end{tabular}



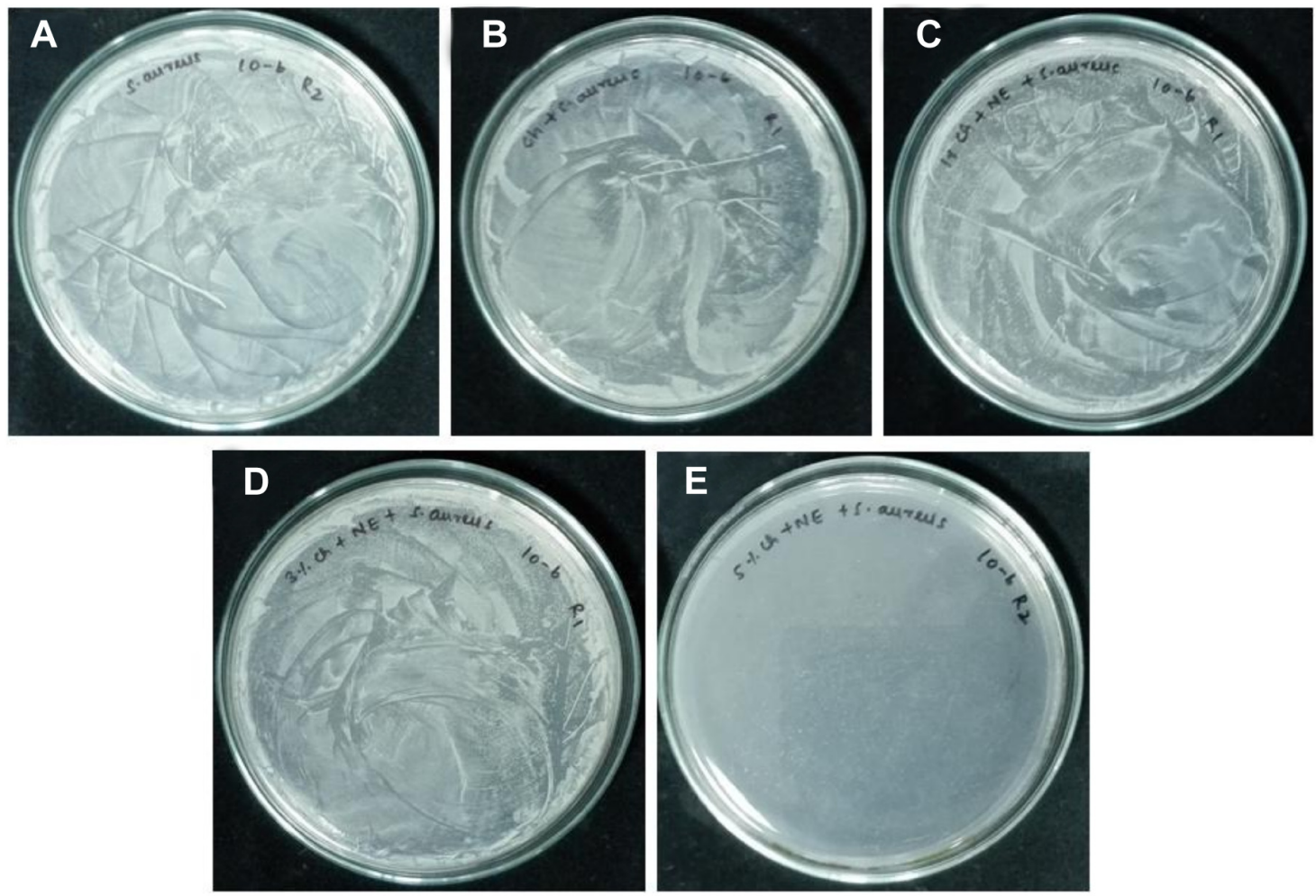

Figure 6 Antibacterial activity of chitosan-only film and NE-CHs by spread plate method on solid medium.

Notes: (A) Staphylococcus aureus. (B) 0\% NE-CH. (C) I\% NE-CH. (D) $3 \% \mathrm{NE}-\mathrm{CH}$. (E) $5 \% \mathrm{NE}-\mathrm{CH}$.

Abbreviation: $\mathrm{NE}-\mathrm{CH}$, nanoemulsion-impregnated chitosan film.

formation on the inner surface of the test tube (Figure 7), and correlated well with the results of the spread plate method. The turbidity of the bacterial cell was highly reduced when treated with 5\% NE-CH film (Figure 7D). The bacteria used in the study were selected as they were found to have

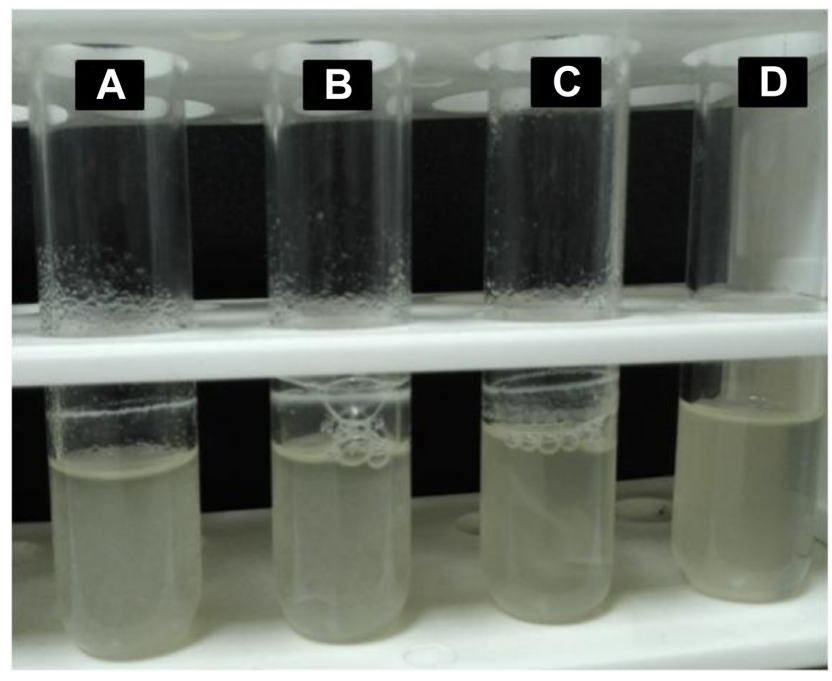

Figure 7 Antibacterial activity of chitosan-only film and NE-CHs by interaction study for 24 hours on liquid medium.

Notes: (A) $0 \% \mathrm{NE}-\mathrm{CH}$. (B) I\% NE-CH. (C) $3 \% \mathrm{NE}-\mathrm{CH}$. (D) $5 \% \mathrm{NE}-\mathrm{CH}$

Abbreviation: $\mathrm{NE}-\mathrm{CH}$, nanoemulsion-impregnated chitosan film. the highest morbidity and mortality associated with wound infections. ${ }^{48,49}$

\section{Conclusion}

Eucalyptus oil nanoemulsion-impregnated chitosan was successfully developed as a thin film. Further physicochemical parameter measurements were carried out to study the interaction between the chitosan and nanoemulsion films. It was observed that the increasing concentration of nanoemulsion in chitosan film produces reduced moisture content. Also, the NE-CH film was found to have enhanced antibacterial activity against the tested clinical pathogen $S$. aureus than chitosan film alone. These findings could justify the inclusion of NE-CH film for wound management in the pharmaceutical industry.

\section{Acknowledgments}

The authors would like to thank VIT University for providing the research work facility and Johnson \& Johnson for sponsoring the research paper to published.

\section{Disclosure}

The authors report no conflicts of interest in this work. 


\section{References}

1. Gilliland EL, Nathwani N, Dore CJ, Lewis JD. Bacterial colonisation of leg ulcers and its effect on success rate of skin grafting. Ann R CollSurg Engl. 1988;70(2):105-108.

2. Diegelmann RF, Evans MC. Wound healing: an overview of acute, fibrotic and delayed healing. Front Biosci. 2004;9:283-289.

3. Dash GK, Murthy PN. Studies on wound healing activity of Heliotropium indicum Linn. leaves on rats. ISRN Pharmacol. 2011;2011:847980.

4. Burt S. Essential oils: their antibacterial properties and potential applications in foods - a review. Int J Food Microbiol. 2004;94:223-253.

5. Inouye S, Takizawa T, Yamaguchi H. Antibacterial activity of essential oils and their major constituents against respiratory tract pathogens by gaseous contact. J Antimicrob Chemother. 2001;47:565-573.

6. Adorjan B, Buchbauer G. Biological properties of essential oils: an updated review. Flavour Frag J. 2010;25(6):407-426.

7. Bașer KHC, Buchbauer G, editors. Handbook of Essential Oils: Science, Technology, and Applications. Boca Raton, FL: CRC Press; 2010.

8. Mason TG, Wilking JN, Meleson K, Chang CB, Graves SM. Nanoemulsions: formation, structure, and physical properties. J Phys Condens Matter. 2006;18:R635-R666.

9. Tadros T, Izquierdo R, Esquena J, Solans C. Formation and stability of nano-emulsions. Adv Colloid Interface Sci. 2004;108-109:303-318.

10. Henry JV, Fryer PJ, Frith WJ, Norton IT. Emulsification mechanism and storage instabilities of hydrocarbon-in-water sub-micron emulsions stabilized with Tweens (20 and 80), Brij 96v and sucrose monoesters. J Colloid Interface Sci. 2009;338:201-206.

11. Sugumar S, Nirmala J, Ghosh V, AnjaliH, MukherjeeA, Chandrasekaran N. Bio-based nanoemulsion formulation, characterization and antibacterial activity against food-borne pathogens. J Basic Microbiol. 2013;53: 677-685.

12. Ghosh V, Mukherjee A, Chandrasekaran N. Ultrasonic emulsification of food-grade nanoemulsion formulation and evaluation of its bactericidal activity. Ultrason Sonochem. 2013;20:338-344.

13. Sugumar S, Ghosh V, Nirmala MJ, Mukherjee A, Chandrasekaran N. Ultrasonic emulsification of eucalyptus oil nanoemulsion: antibacterial activity against Staphylococcus aureus and wound healing activity in Wistar rats. Ultrason Sonochem. 2014;21:1044-1049.

14. Dreifke MB, Jayasuriya AA, Jayasuriya AC. Current wound healing procedures and potential care. Mater Sci Eng C Mater Biol Appl. 2015; 48:651-662.

15. Sánchez-González L, Cháfer M, Chiralt A, González-Martínez C. Physical properties of edible chitosan films containing bergamot essential oil and their inhibitory action on Penicillium italicum. Carbohydr Polym. 2010;82:277-283.

16. Rubilar JF, Cruz RMS, Silva HD, Vicente AA, Khmelinskii I, Vieira MC. Physico-mechanical properties of chitosan films with carvacrol and grape seed extract. J Food Eng. 2013;115:466-474.

17. Zhong Y, Song X, Li Y. Antimicrobial, physical and mechanical properties of kudzu starch-chitosan composite films as a function of acid solvent types. Carbohydr Polym. 2011;84:335-342.

18. Premraj R, Doble M. Biodegradation of polymers. Indian J Biotechnol. 2005;4:186-193.

19. Rinaudo M. Chitin and chitosan: properties and applications. Prog Polym Sci. 2006;31:603-632.

20. Muzzarelli RAA. Chitin. London: Pergamon Press; 1977:326.

21. Habibi Y, Lucia LA, editors. Polysaccharide Building Blocks: A Sustainable Approach to the Development of Renewable Biomaterial. New York: John Wiley \& Sons, Inc; 2012:pp. 1-409.

22. Vásconez MB, Flores SK, Campos CA, Alvarado J, Gerschenson LN. Antimicrobial activity and physical properties of chitosan-tapioca starch based edible films and coatings. Food Res Int. 2009;42:762-769.

23. Enescu D, Olteanu CE. Functionalized chitosan and its use in pharmaceutical, biomedical and biotechnological research. Chem Eng Commun. 2008;195:1269-1291.

24. Senel S, McClure SJ. Potential applications of chitosan in veterinary medicine. Adv Drug Deliv Rev. 2004;56:1467-1480.
25. Ueno H, Yamada H, Tanaka I, et al. Accelerating effects of chitosan for healing at early phase of experimental open wound in dogs. Biomaterials. 1999;20:1407-1414.

26. Agrawal P, Soni S, Mittal G, Bhatnagar A. Role of polymeric biomaterials as wound healing agents. Int J Low Extrem Wounds. 2014;13(3): 180-190.

27. Shi Y, Ma L, Zhou J, Mao Z, Gao C. Collagen/chitosan - silicone membrane bilayer scaffold as a dermal equivalent. Polymer Adv Tech. 2006; 16:789-794.

28. Noel SP, Courtney H, Bumgardner JD, Haggard WO. Chitosan films: a potential local drug delivery system for antibiotics. Clin Orthop Relat Res. 2008;466:1377-1382.

29. Zivanovic S, Chi S, Draughon AF. Antimicrobial activity of chitosan films enriched with essential oils. J Food Sci. 2005;70:45-51.

30. Gómez-Estaca J, López de Lacey A, López-Caballero ME, GómezGuillén MC, Montero P. Biodegradable gelatin-chitosan films incorporated with essential oils as antimicrobial agents for fish preservation. Food Microbiol. 2010;27:889-896.

31. Pasanphan W, Buettner GR, Chirachanchai S. Chitosan gallate as a novel potential polysaccharide antioxidant: an EPR study. Carbohydr Res. 2010;345:132-140.

32. Altiok D, Altiok E, Tihminlioglu F. Physical, antibacterial and antioxidant properties of chitosan films incorporated with thyme oil for potential wound healing applications. J Mater Sci Mater Med. 2010;21: 2227-2236.

33. Peng Y, Li Y. Combined effects of two kinds of essential oils on physical, mechanical and structural properties of chitosan films. Food Hydrocoll. 2014;36:287-293.

34. Ojagh SM, Rezaei M, Razavi SH, Hosseini SMH. Development and evaluation of a novel biodegradable film made from chitosan and cinnamon essential oil with low affinity toward water. Food Chem. 2010; 122:161-166.

35. Casariego A, Souza BWS, Vicente AA, Teixeira JA, Cruz L, Díaz R. Chitosan coating surface properties as affected by plasticizer, surfactant and polymer concentrations in relation to the surface properties of tomato and carrot. Food Hydrocoll. 2008;22:1452-1459.

36. Sugumar S, Clarke SK, Nirmala MJ, Tyagi BK, Mukherjee A, Chandrasekaran N. Nanoemulsion of eucalyptus oil and its larvicidal activity against Culex quinquefasciatus. Bull Entomol Res. 2014;104: 393-402.

37. Sugumar S, Singh S, Mukherjee A, Chandrasekaran N. Nanoemulsion of orange oil with non ionic surfactant produced emulsion using ultrasonication technique: evaluating against food spoilage yeast. Appl Nanosci. 2015;1-9: doi: 10.1007/s13204-015-0412-z.

38. Ghosh V, Saranya S, Mukherjee A, Chandrasekaran N. Cinnamon oil nanoemulsion formulation by ultrasonic emulsification: investigation of its bactericidal activity. J Nanosci Nanotechnol. 2013;13:114-122.

39. Bourbon AI, Pinheiro AC, Cerqueira MA, et al. Physico-chemical characterization of chitosan-based edible films incorporating bioactive compounds of different molecular weight. J Food Eng. 2011;106: 111-118.

40. Shojaee-Aliabadi S, Hosseini H, Mohammadifara MA, et al. Characterization of $\kappa$-carrageenan films incorporated plant essential oils with improved antimicrobial activity. Carbohydr Polym. 2014;101:582-591.

41. Wu J, Zhong F, Li Y, Shoemaker CF, Xia W. Preparation and characterization of pullulan-chitosan and pullulan-carboxymethyl chitosan blended films. Food Hydrocolloid. 2013;30(1):82-91.

42. Pastor C, Sánchez-González L, Chiralt A, Cháfer M, González-Martínez C. Physical and antioxidant properties of chitosan and methylcellulose based films containing resveratrol. Food Hydrocoll. 2013;30(1):272-280.

43. Paluszkiewicz C, Stodolak E, Hasik M, Blazewicz M. FT-IR study of montmorillonite-chitosan nanocomposite materials. Spectrochim Acta A Mol Biomol Spectrosc. 2010;79(15):784-788.

44. Cerqueira MA, Souza BWS, Teixeira JA, Vicente AA. Effect of glycerol and corn oil on physicochemical properties of polysaccharide films A comparative study. Food Hydrocoll. 2012;27:175-184. 
45. Hosseini MH, Razavi SH, Mousavi MA. Antimicrobial, physical and mechanical properties of chitosan-based films incorporated with thyme, clove and cinnamon essential oils. J Food Process Preserv. 2009;33: 727-743.

46. Broumand A, Emam-Djomeh Z, Hamedi M, Razavi SH. Antimicrobial, water vapour permeability, mechanical and thermal properties of casein based Zataraia multiflora Boiss. Extract containing film. LWT - Food Science and Technology. 2011;44(10):2316-2323.

47. Coma V, Martial-Gros A, Garreau S, Copinet A, Salin F, Deschamps A. Edible antimicrobial films based on chitosan matrix. J Food Sci. 2002; 67:1162-1169.
48. Rujitanaroj PO, Pimpha N, Supaphol P. Wound-dressing materials with antibacterial activity from electrospun gelatin fiber mats containing silver nanoparticles. Polymer. 2008;49:4723-4732.

49. Harkins AL, Duri S, Kloth LC, Tran CD. Chitosan-cellulose composite for wound dressing material. Part 2. Antimicrobial activity, blood absorption ability, and biocompatibility. J Biomed Mater Res B Appl Biomater. 2014;102(6):1199-1206.

\section{Publish your work in this journal}

The International Journal of Nanomedicine is an international, peerreviewed journal focusing on the application of nanotechnology in diagnostics, therapeutics, and drug delivery systems throughout the biomedical field. This journal is indexed on PubMed Central, MedLine, CAS, SciSearch $®$, Current Contents $® /$ Clinical Medicine,

\section{Dovepress}

Journal Citation Reports/Science Edition, EMBase, Scopus and the Elsevier Bibliographic databases. The manuscript management system is completely online and includes a very quick and fair peer-review system, which is all easy to use. Visit http://www.dovepress.com/ testimonials.php to read real quotes from published authors.

Submit your manuscript here: http://www.dovepress.com/international-journal-of-nanomedicine-journal 